Jose Florencio F. Lapeña Jr., MA, MD

Department of Otorhinolaryngology College of Medicine - Philippine General Hospital University of the Philippines Manila
Correspondence: Jose Florencio F. Lapeña Jr., MA, MD Department of Otorhinolaryngology Ward 10, Philippine General Hospital Taft Ave., Ermita, Manila 1000

Phone (632) 5264360 Fax (632) 5255444

Email:pjohns@psohns.org.ph

No funding support was received for this study. The author signed a disclosure that he has no proprietary or financial interest with any organization that may have a direct interest in the subject matter of this manuscript, or in any product used or cited in this article.

Adapted, with permission, from the manuscript "Runny nose, rhinitis and sinusitis" accepted for inclusion in the Textbook on Family Medicine, Unit 4.2.2.2 Ambulatory Care: Head \& Neck EENT (Forthcoming).

\section{Primary Care Evaluation of the Nose and Paranasal Sinuses}

Primary care evaluation of the nose and paranasal sinuses begins with inspection. The astute clinician will seldom miss the hyperemic nose and open-mouth breathing of nasal congestion, the "long-face" facies, infraorbital dark "shiners" and edema of decreased lymphatic drainage from chronic nasal obstruction, and the transverse nasal crease from repeated performance of the "allergic salute" in allergic rhinitis. Tearing may be caused by inferior obstruction of the nasolacrimal duct. Widening of the nasal bridge (Woake's syndrome) may suggest massive nasal polyposis ${ }^{2}$. The patient with acute sinusitis may be in obvious pain and actually avoid jarring movements, and orbital complications of acute sinusitis should be apparent even to the untrained eye. A polished mirror or metal tongue depressor gently held under both nostrils can document patency of both nasal airways by observing the misting pattern even before looking inside the nose. Glatzel's mirror test ${ }^{3}$ attempts to measure this pattern but mere observation for symmetry establishes expiratory patency. Inspiratory obstruction can be assessed by gently pulling the ipsilateral cheek laterally. If it relieves nasal obstruction (positive Cottle's sign ${ }^{4}$ ), the source of obstruction is in the nasal valve area and may be surgically correctible.

Anterior rhinoscopy is best done using coaxial binocular illumination such as provided by a properly focused head mirror and bright light source. Alternately, a lumiview ${ }^{\mathrm{TM}}$ (Welch Allyn Corporation, New York, USA) or hand-held otoscope with the largest available clean ear speculum can be used. In babies and young children, gently flipping up the nasal tip with a finger facilitates viewing the nasal cavities. Adult noses are best viewed by aligning the external (downward-facing) and internal (forward-facing) nares with the aid of a nasal speculum. With the thumb on the pivot and index finger resting on the nasal tip, the prongs should be pressed by the remaining digits against the palm and spread superiorly against compliant alae rather than medially toward the septum. Insertion should be restricted to the vestibular area (alae nasi); insinuation beyond the internal nares (limen nasi) is painful, as is closing the speculum before withdrawing (pinching vibrissae). Decongestion should be performed in the presence of congested or hypertrophic turbinates and to distinguish the latter from nasal polyps (which do not shrink even with decongestion). Commercially available oxymetazoline $0.05 \%$ and $0.025 \%$ (Drixine $^{\mathrm{TM}}$ ) or tetrahydrozoline $0.1 \%$ (Sinutab NS ${ }^{\mathrm{TM}}$ ) nasal solutions should be gently dropped into each nostril while the head is tilted back and nasal tip upturned. The nozzle should not touch the nose at any time. Three to five drops are instilled in one nostril after which the head is turned so that the ipsilateral ear faces down. This position (after Proetz) ${ }^{5}$ facilitates the solution spreading to the lateral wall of the nose while the patient gently sniffs in. The maneuver is then replicated for 


\section{PRACTICE PEARLS}
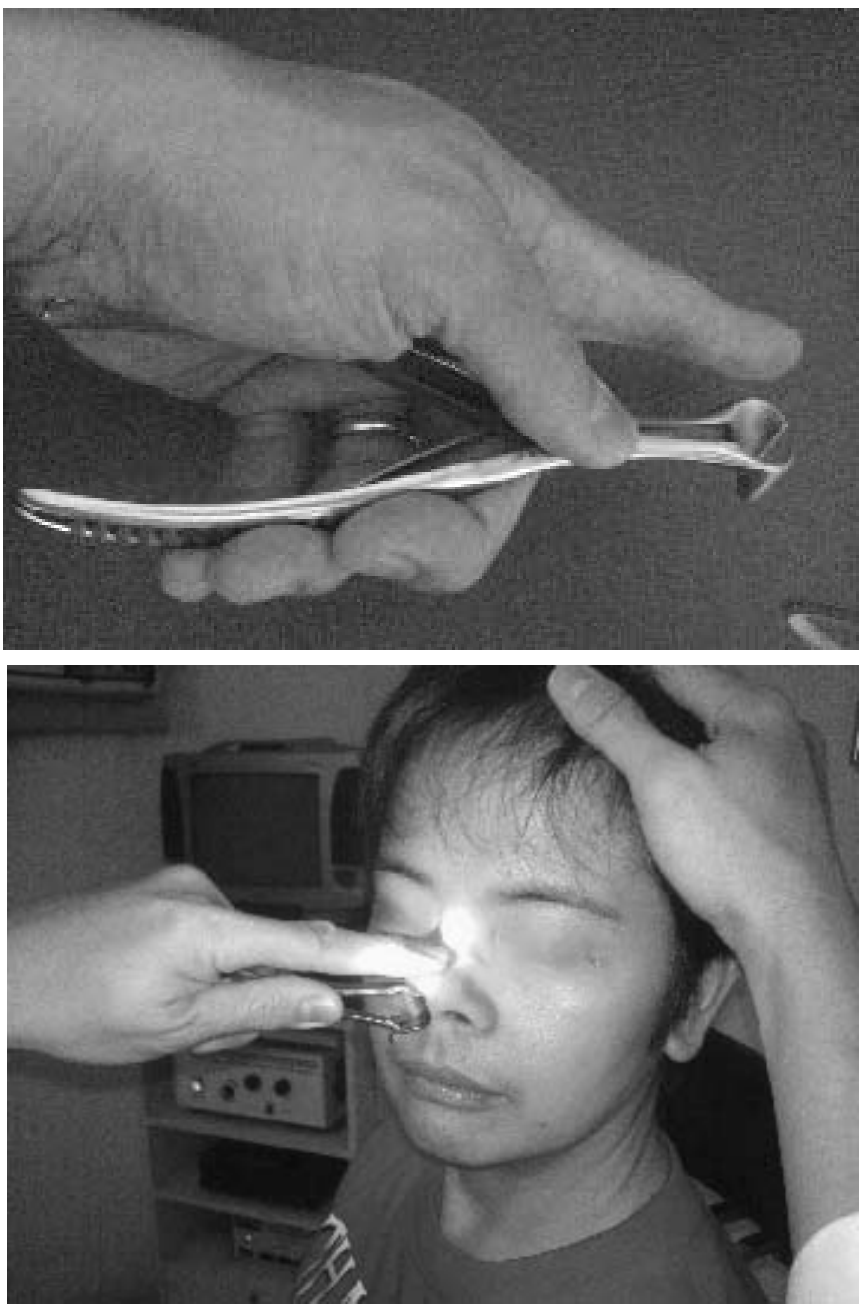

the other nostril. Three to five drops solution are then instilled in both nostrils a second time and the patient is asked to lower the forehead between the knees or to assume a knee-chest (mecca) position with forehead on the floor which facilitates spreading solution to the roof of the nose ${ }^{6}$. Adequate decongestion not only facilitates examination of the nasal cavities; it affords relief from obstruction and drainage of retained discharges. Performing the Proetz and mecca maneuvers also educates the patient in the proper way to continue decongestion at home, provided dosing duration (three to five days) and regimens (twelve hourly for oxymetazoline and eight hourly for tetrahydrozoline) are not exceeded due to the danger of rebound rhinitis. The maneuvers are also useful for nasal saline douches and instilling steroid sprays.

Palpation of the paranasal sinuses is performed by percussion or by pressing firmly but gently over the most accessible points of maximum tenderness for each sinus: the vertex (sphenoid), supero-medial roofs of the orbital sockets (frontal), nasal bones between medial canthi (ethmoid) and incisive fossa area of cheeks (maxillary). Upper jaw teeth (especially canines) may be tender when tapped gently in cases of acute maxillary sinusitis. Transillumination with a powerful light source in a darkened room may suggest the presence of fluid or masses in the frontal and maxillary sinuses. Normal air-filled frontal and maxillary sinuses should "light up" (transilluminate) with light applied over their respective palpation points. External maxillary transillumination also casts a red glow on the hard palate, and a"red streak" in the lateral recess of the oropharynx may predict sinusitis ${ }^{7}$. Better results are achieved for the maxillary sinus with transoral light against the hard palate on each side. Transillumination is positive (normal) for the maxillary sinuses when the cheeks turn red-orange, a red-orange crescent lights up the infraorbital rim, and a red-orange papillary reflex is observed on downward gaze; or when the scalloped margins and inter-sinus septum of the frontal sinuses stand out in relief against a red-orange background. Opacification can be produced by fluid, masses or hypoplastic sinuses while air-fluid levels produce a combination of findings. Swelling, masses, infraorbital nerve hyposthesia and extraocular muscle motion limitations warrant urgent specialist referral.

\section{REFERENCES:}

1 Lapeña, JF, Isidro - Lapeña, JS. Runny nose, rhinitis and sinusitis. In: Leopando ZE (Ed) Textbook on family medicine. Philippine academy of family physicians. Makati City: Graphic-line Enterprises; 2006 (Forthcoming).

Kellerhals B, Uthemann B. Woakes' syndrome: the problems of infantile nasal polyps. Int J Pediatr Otorhinlaryngol. 1979; 1:79-85.

Lieb CC, Mulinos MG. Nasograph mirror of glatzel as a measure of nasal patency. Arch Otolaryngol. 1939; 30: 334-343.

Cottle MH. The structure and function of nasal vestibule. Arch Otolaryngol. 1955; 62: 173-181.

5 Proetz AW. Displacement irrigation of nasal sinuses Arch Otolaryngol 1926; 4: 1-12.

6 Evans KL. Diagnosis and management of sinusitis. BMJ 1994; 309: 1415-1422.

7 Thomas C, Aizin V. Brief report: a red streak in the lateral recess of the oropharynx predicts acute sinusitis. J Gen Intern Med 2006 Sept.; 21(9):986-88. 